\title{
Parâmetros sanguíneos de vacas leiteiras suplementadas com diferentes fontes de gordura
}

\author{
Blood parameters of dairy cows supplemented with different fat sources
}

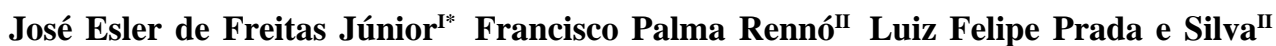 \\ Jefferson Rodrigues Gandra ${ }^{\mathrm{I}}$ Milton Maturana Filho ${ }^{\mathrm{I}}$ Carla Foditsch $^{\mathrm{III}}$ Beatriz Conte Venturelli ${ }^{\mathrm{I}}$
}

\section{RESUMO}

O objetivo deste trabalho foi avaliar a utilização de diferentes fontes de gordura nas rações de vacas em lactação $e$ seus efeitos sobre o consumo de matéria seca e as concentrações dos parâmetros sangüíneos. Foram utilizadas 12 vacas da raça Holandês, agrupadas em três quadrados latinos balanceados $4 \times 4$ e alimentadas com as seguintes rações: 1) controle; 2) óleo de soja refinado; 3) grão de soja in natura; e 4) sais de cálcio de ácidos graxos (Megalac-E). As concentrações de colesterol total, colesterol, lipoproteína de baixa densidade ( $L D L)$ e colesterol de alta densidade (HDL) foram maiores $(P<0,05)$ para as vacas alimentadas com as rações contendo fontes de gordura em relação à ração controle. As concentrações de uréia e nitrogênio ureico no soro foram semelhantes entre as rações utilizadas, com exceção da ração contendo sais de cálcio de ácidos graxos, que apresentou concentrações menores $(P<0,05)$. O consumo de matéria seca foi menor $(P<0,05)$ nas vacas que receberam sais de cálcio nas rações. Os animais que receberam a ração contendo grão de soja como fonte de gordura apresentaram menor $(P<0,05)$ produção de leite quando comparada às demais rações utilizadas. A utilização de fontes de gordura em rações de vacas em lactação alterou os parâmetros sanguíneos, dependendo da fonte de gordura utilizada.

Palavras-chave: lipídios, enzimas hepáticas, perfil metabólico, lipidograma, proteinograma.

\section{ABSTRACT}

This study was carried out to evaluate the use of different fat sources in dairy cows rations and its effects on dry matter intake, milk yield and composition, and blood parameter. Twelve Holstein cows were allocated in three balanced latin square $4 \times 4$, and fed with the following rations: 1) Control, with $2.5 \%$; 2) Refined soybean oil; 3) Whole soybean; and 4), Calcium salts of fatty acids (Megalac-E). The concentrations of total cholesterol and lipoprotein low density $(L D L)$ were higher $(P<0.05)$ for cows that received rations with fat sources, which also causes increased $(P<0.05) e$ concentration of high density lipoprotein (HDL). The concentrations of urea and blood urea nitrogen were similar among the rations, except for the diet containing calcium salts of fatty acids, which showed lower $(P<0.05)$. The dry matter intake was lower $(P<0.05)$ in cows that received calcium salts in the rations. The animals that received a diet containing whole soybeans as a source of fat had lower $(P<0.05)$ yield milk when compared to other rations used. The use of fat sources in dairy cows rations influenced the blood parameters, especially for parameters related to lipidogram.

Key words: lipids, lipidogram, liver enzymes, profile metabolic, proteinogram.

\section{INTRODUÇÃO}

A utilização de fontes de gordura suplementar tem sido prática comum na alimentação de vacas em lactação, especialmente por permitir maior aporte de energia para a síntese de leite e de seus componentes (STAPLES et al., 2001). Entretanto, é preciso considerar que, para vacas em lactação, o uso de gordura pode promover variáveis respostas no desempenho produtivo, além de mudanças no perfil metabólico, e a resposta à suplementação depende da

'Programa de Pós-graduação em Nutrição e Produção Animal, Faculdade de Medicina Veterinária e Zootecnia (FMVZ), Universidade de São Paulo (USP). Av. Duque de Caxias Norte, n. 225, Bairro Jardim Elite, 13635-900, Pirassununga, SP, Brasil. E-mail: joseeslerfjr@usp.br. *Autor para correspondência.

IIDepartamento de Nutrição e Produção Animal, FMVZ, USP, Pirassununga, SP, Brasil.

IIIFMVZ/USP, Pirassununga, SP, Brasil. 
dieta basal fornecida (especialmente o volumoso), do estágio de lactação, do balanço energético, da composição e da quantidade da fonte de gordura utilizada (ONETTI \& GRUMMER, 2004).

Para diagnóstico e estudo da avaliação de alimentos na nutrição animal, tem sido empregado o uso dos perfis metabólicos, por meio de análises sanguíneas de grupos representativos de animais de um rebanho, seu grau de adequação nas principais vias metabólicas relacionadas com energia, proteínas e minerais, bem como a funcionalidade de órgãos vitais.

DIRKSEN \& BREITNER (1993) comentam que os componentes bioquímicos sanguíneos mais comumente determinados no perfil metabólico representam as principais vias metabólicas do organismo, das quais a glicose, o colesterol e o betahidroxibutirato representam o metabolismo energético; a uréia, a hemoglobulina, as globulinas, a albumina e as proteínas totais representam o metabolismo protéico; e o cálcio, o fósforo inorgânico, o magnésio, o sódio e o potássio representam os macrominerais (WITTWER \& CONTRERAS, 1980). Adicionalmente, são estudados metabólitos indicadores do funcionamento hepático, tais como as enzimas AST (aspartato aminotransferase), GGT (gama-glutamiltransferase) e $\gamma \mathrm{GT}$ (glutamato desidrogenase), bem como albumina, colesterol total e suas frações LDL, VLDL e HDL, representando o lipidograma completo (GONZALEZ, 1997).

Por isso, variações dos metabólicos sanguíneos em vacas leiteiras permitem estimar o processo de adaptação metabólica a novas situações fisiológicas ou de alimentação. De acordo com CHRISTENSEN et al. (1994), o metabolismo ruminal, a absorção intestinal, o transporte sistêmico, o metabolismo sistêmico, a secreção e a deposição de gordura no organismo são aspectos diretamente ligados ao metabolismo de lipídios e podem influenciar os parâmetros sanguíneos em animais recebendo gordura nas rações. Entretanto, é preciso considerar que, além da fase de lactação, o nível de produção também reflete mudanças no padrão do perfil metabólico em vacas em produção.

Dessa forma, o objetivo deste estudo foi avaliar as concentrações dos parâmetros sanguíneos de vacas leiteiras suplementadas com diferentes fontes de gordura nas rações.

\section{MATERIAL E MÉTODOS}

Este experimento foi conduzido no Confinamento Experimental da Prefeitura do Campus Administrativo de Pirassununga, na Universidade de São Paulo. Foram utilizadas 12 vacas da raça Holandês multíparas, com peso vivo médio de $580 \mathrm{~kg}$, média de 135 dias de lactação e produção média de $25,0 \mathrm{~kg} \mathrm{vaca}^{-1}$ $\mathrm{dia}^{-1}$. Os animais foram agrupados em três quadrados latinos $4 \times 4$ balanceados em função dos dias em lactação, com duração do período experimental de 19 dias, sendo 12 dias de adaptação e sete dias de coleta de amostras.

Foram utilizadas as seguintes rações experimentais, formuladas segundo o NRC (2001): 1) controle (C), composto por ração de aproximadamente $2,5 \%$ de extrato etéreo na matéria seca (EE);2) óleo de soja (OS), composto por ração com aproximadamente $5,5 \%$ de EE, baseada na inclusão de 3,0\% de óleo de soja refinado no concentrado; 3 ) grão de soja (GS), composto por ração com aproximadamente 5,5\% de EE, baseada na inclusão de grão de soja "in natura" no concentrado; e 4) sais de cálcio de ácidos graxos insaturados (SC) (MEGALAC-E, Química Geral do Nordeste e Arm \& Hammer, Inc.), composto por ração com aproximadamente 5,5\% de EE, baseada na inclusão de 3,0\% de sais de cálcio no concentrado. Durante o período experimental, foi utilizada a silagem de milho como volumoso, e os respectivos concentrados, água e sal mineral foram fornecidos ad libitum.

Diariamente, foram realizadas pesagens das quantidades dos volumosos e concentrados fornecidos e das sobras de cada ração experimental, para estimativa do consumo individual. Os animais foram arraçoados de acordo com o consumo de matéria seca no dia anterior, de forma a ser mantido porcentual de sobras das dietas, diariamente, entre 5 e $10 \%$ do fornecido para não haver limitação de consumo (a proporção dos ingredientes e a respectiva composição bromatológica das rações experimentais encontram-se na tabela 1). As amostras dos alimentos fornecidos foram coletadas e armazenadas a $-20^{\circ} \mathrm{C}$, para posteriores análises químico-bromatológicas.

Nos alimentos fornecidos e nas amostras de sobras, foram analisados os teores de matéria seca (MS), matéria orgânica (MO), matéria mineral (MM), extrato etéreo $(\mathrm{EE})$, proteína bruta $(\mathrm{PB})$, nitrogênio insolúvel em detergente neutro (NIDN), nitrogênio insolúvel em detergente ácido (NIDA) e lignina de acordo com as metodologias descritas por SILVA \& QUEIROZ (2002). O teor de proteína bruta (PB) foi obtido pela multiplicação do teor de nitrogênio total por 6,25. O extrato etéreo foi determinado pelo método "a quente", com a utilização éter de petróleo como solvente em aparelho para extração de gordura tipo Goldfisch utilizando extratores equipados com suporte de vidro e tubos coletores de éter ou Soxhlet. Foram pesadas cerca de 2,0g das amostras em papel filtro Whatman $n^{\circ} 1$ e posteriormente submetidas à extração 
Tabela 1- Composição percentual e bromatológica das rações experimentais com base na matéria seca (\%ms).

\begin{tabular}{|c|c|c|c|c|}
\hline \multirow{2}{*}{ Ingredientes $(\%)$} & \multirow[b]{2}{*}{ Controle } & \multirow[b]{2}{*}{ Óleo de soja } & \multirow[b]{2}{*}{ Grão de soja } & \multirow[b]{2}{*}{ Sais de cálcio ${ }^{1}$} \\
\hline & & & & \\
\hline Silagem de milho & 58,00 & 58,00 & 58,00 & 58,00 \\
\hline Milho moído & 21,90 & 18,90 & 18,72 & 18,90 \\
\hline Farelo de soja & 16,42 & 16,42 & 3,61 & 16,42 \\
\hline Óleo de soja & - & 3,00 & - & - \\
\hline Grão de soja & - & - & 16,00 & - \\
\hline Sais de cálcio de ácidos graxos & - & - & - & 3,00 \\
\hline Ureia & 0,73 & 0,73 & 0,72 & 0,73 \\
\hline Sulfato de amônia & 0,05 & 0,05 & 0,05 & 0,05 \\
\hline Bicarbonato de sódio & 0,62 & 0,62 & 0,62 & 0,62 \\
\hline Óxido de magnésio & 0,02 & 0,02 & 0,02 & 0,02 \\
\hline Mistura mineral $^{2}$ & 1,96 & 1,96 & 1,96 & 1,96 \\
\hline Calcáreo & 0,10 & 0,10 & 0,10 & 0,10 \\
\hline Sal comum & 0,20 & 0,20 & 0,20 & 0,20 \\
\hline \multicolumn{5}{|l|}{ Composição química } \\
\hline Matéria seca ${ }^{3}$ & 52,86 & 53,20 & 53,15 & 53,13 \\
\hline Matéria orgânica & 91,49 & 91,64 & 91,67 & 90,90 \\
\hline Proteína bruta & 17,81 & 17,50 & 17,10 & 17,50 \\
\hline $\mathrm{Nidn}^{4}$ & 14,85 & 14,42 & 16,81 & 14,42 \\
\hline $\mathrm{Nida}^{5}$ & 10,77 & 10,50 & 10,68 & 10,50 \\
\hline Extrato etéreo & 2,81 & 5,65 & 4,85 & 5,11 \\
\hline Carboidratos totais & 71,20 & 68,47 & 69,73 & 68,32 \\
\hline Fibra em detergente neutro & 41,45 & 41,01 & 43,15 & 41,01 \\
\hline $\operatorname{Fdn}_{\mathrm{cp}}{ }^{6}$ & 38,56 & 38,18 & 39,37 & 38,18 \\
\hline Carboidratos não fibrosos & 37,27 & 35,21 & 34,12 & 35,06 \\
\hline $\mathrm{Cnf}_{\mathrm{cp}}^{7}$ & 38,11 & 36,04 & 35,83 & 35,98 \\
\hline Fibra em detergente ácido & 26,93 & 27,79 & 26,93 & 24,79 \\
\hline Lignina & 3,27 & 3,24 & 4,09 & 3,24 \\
\hline Matéria mineral & 7,60 & 7,55 & 7,54 & 7,55 \\
\hline Nutrientes digestíveis totais ${ }^{8}$ & 67,33 & 70,19 & 69,12 & 69,34 \\
\hline $\mathrm{El}_{1}^{9}(\mathrm{mcal} / \mathrm{kg})$ & 1,62 & 1,73 & 1,73 & 1,70 \\
\hline
\end{tabular}

${ }_{2}^{1} \mathrm{sc}=$ sais de cálcio de ácidos graxos (megalac-E).

2 composição por quilograma de produto: cálcio-190g; fósforo-73g; enxofre-30g; magnésio-44g; cobre-340mg; zinco-1350mg; manganês-940mg cobalto-3mg; iodo-16mg; selênio-10mg; ferro-1064mg; vit, a-100000, vit, d-40000 e vit, e-600,0.

${ }^{3} \%$ matéria natural. ${ }^{4}$ nitrogênio solúvel em detergente neutro (\%nt). ${ }^{5}$ nitrogênio solúvel em detergente ácido (\%nt). ${ }^{6}$ fibra em detergente neutro livre de cinzas e proteína. ${ }^{7}$ carboidratos não fibrosos livre de cinzas e proteína. ${ }^{8,9}$ estimado pelas equações do NRC (2001).

por quatro horas com aquecedores ajustados para máxima temperatura com velocidade de condensação de cinco a seis gotas por segundo.

Os carboidratos totais (CT) foram calculados segundo SNIFFEN et al. (1992), em que: CT=100 (\%PB+\%EE+\%MM). Os teores de carboidratos não fibrosos (CNF) foram estimados segundo HALL (1998), em que: $C N F=100-[(\% \mathrm{~PB}-\% \mathrm{~PB}$ Uréia $+\%$ Uréia) $+\% \mathrm{EE}+\% \mathrm{MM}+\% \mathrm{FDN}]$. Os nutrientes digestíveis totais foram calculados conforme equações do NRC (2001), em que: NDT=CNFD+PBD+(AGD*2,25)+FDND - 7, em que PBD, CNFD, FDND e AGD representam o total desses nutrientes digestíveis. Os nutrientes digestíveis totais observados $\mathrm{NDT}=\mathrm{PBd}+\mathrm{FDNd}+(\mathrm{EEd}$ $* 2,25)+\mathrm{CNFd}$ foram calculados de acordo com WEISS et al. (1992). Os teores de fibra detergente neutro (FDN), fibra detergente neutro livre de cinza e proteína (FDNcp), e fibra detergente ácido (FDA) foram obtidos conforme método descrito por VAN SOEST \& MASON, (1991), utilizando-se a-amilase sem adição de sulfito de sódio na determinação do FDN, em sistema Ankon.

As vacas foram ordenhadas mecanicamente duas vezes ao dia, às $6 \mathrm{~h} 30 \mathrm{~min}$ e às $15 \mathrm{~h} 30 \mathrm{~min}$, sendo a produção de leite registrada diariamente durante todo o período experimental. A produção de leite foi corrigida para $3,5 \%$ de gordura (PLC), segundo fórmula de 
SKLAN et al., (1992), em que PLC $=(0,432+0,1625 *$ teor de gordura do leite) $* \mathrm{~kg}$ de leite.

Para determinação da uréia e do nitrogênio ureico no leite, as amostras de leite foram desproteinizadas, em que $10 \mathrm{ml}$ de leite foram misturados a $5 \mathrm{ml}$ de ácido tricloroacético a $25 \%$, em becker de $50 \mathrm{ml}$. As amostras foram deixadas em repouso por cinco minutos. Posteriormente, as amostras foram filtradas em papel filtro, sendo o leite fluido filtrado e transferido para ependorffs de $2,5 \mathrm{ml}$, e armazenadas em freezer, a $20^{\circ} \mathrm{C}$. As análises da concentração de uréia no leite desproteinizado foram realizadas no Laboratório de Bioquímica e Fisiologia Animal do Departamento de Nutrição e Produção Animal da FMVZ-USP, por meio de kits comerciais $\left(\right.$ Laborlab $^{\circledR}$ e CELM $^{\circledR}$ ). A concentração de nitrogênio ureico no leite foi determinada indiretamente por meio da seguinte fórmula: Nitrogênio ureico=ureia $\left(\mathrm{mg} \quad \mathrm{dl}^{-1}\right) / 2,14 \quad($ GUTMANN \& BERGMEYER, 1974).

As coletas de sangue foram realizadas no 16을 dia de cada período experimental por punção da veia e/ou artéria coccígea, anteriormente ao fornecimento das rações no período da manhã. As amostras foram coletadas em tubos vacuolizados (vacutainer) de $10 \mathrm{~mL}$, para dosagem dos parâmetros sanguíneos triglicerídeos, colesterol total, colesterolHDL, proteínas totais, albumina, uréia, e as concentrações das enzimas aspartato aminotransferase (AST) gama glutamil transferase (GTA) e fosfatase alcalina (FA), no soro. Para a dosagem das concentrações de glicose no plasma o sangue foi coletado em tubos contendo fluoreto de sódio. Imediatamente após a coleta, as amostras foram refrigeradas e centrifugadas a $2000 \mathrm{~g}$, durante 15 minutos, para a separação do soro ou plasma. O centrifugado obtido foi transferido para tubetes plásticos, identificados e armazenados a $-20^{\circ} \mathrm{C}$, até o procedimento das análises laboratoriais.

As análises das concentrações dos parâmetros sanguíneos foram realizadas no Laboratório de Bioquímica e Fisiologia Animal do Departamento de Nutrição e Produção Animal da FMVZ-USP, por meio de kits comerciais $\left(\right.$ Laborlab $^{\circledR}$ e CELM $^{\circledR}$ ) que utilizam método enzimático colorimétrico de ponto final, sendo a leitura realizada em analisador automático de bioquímica sanguínea (Sistema de Bioquímica Automático SBA-200 - CELM $^{\circledR}$ ).

A concentração de Colesterol HDL (C-HDL) foi determinada em duas etapas, sendo a primeira envolvendo preparação prévia das amostras, e a segunda envolvendo a análise propriamente dita. Para a realização da análise da concentração de C-HDL, $200 \mu 1$ da amostra foram pipetados em tubos Ependorff de $2,5 \mathrm{ml}$, juntamente com $100 \mu 1$ do reativo único precipitante (CELM-1763), na proporção de 2:1, e misturados manualmente por inversão suave durante 20 segundos. Em seguida, as amostras foram deixadas em repouso, por 10 minutos. Posteriormente, as amostras preparadas foram centrifugadas durante 15 minutos a $2700 \mathrm{~g}$. Nos volumes centrifugados, as lipoproteínas LDL e VLDL foram precipitadas seletivamente pelo ácido fosfotungstico. No sobrenadante, separado pela centrifugação, restaram as moléculas de HDL ligadas ao colesterol (Friedewald et al.,1972).

Os dados obtidos foram submetidos à análise de variância e ao teste de média (Tukey), utilizando-se o programa SAS 1999, versão 8.0, e adotando-se nível de significância de 5\%.

\section{RESULTADOS E DISCUSSÃO}

O consumo de matéria seca (Tabela 2 ) foi semelhante $(\mathrm{P}>0,05)$ entre as rações de controle e as que utilizaram fontes de gordura, com exceção dos animais submetidos à ração contendo sais de cálcio, que apresentaram menor consumo $(\mathrm{P}<0,05)$. Esse resultado pode ser atribuído à aceitabilidade dessa fonte de gordura pelos animais. ALLEN (2000) avaliou vários experimentos que utilizaram rações contendo

Tabela 2 - Médias e coeficientes de variação (cv) para o consumo de matéria seca (cms), produção de leite (pl) e produção de leite corrigida (plc), obtidos para as rações experimentais.

\begin{tabular}{|c|c|c|c|c|c|c|}
\hline \multirow{2}{*}{ Variáveis } & \multirow[b]{2}{*}{ Controle } & \multirow[b]{2}{*}{ Óleo de soja } & \multirow[b]{2}{*}{ Grão de soja } & \multirow[b]{2}{*}{ Sais de cálcio ${ }^{1}$} & \multirow{2}{*}{ Médias } & \multirow{2}{*}{$\mathrm{Cv}(\%)$} \\
\hline & & & & & & \\
\hline $\mathrm{Cms}\left(\mathrm{kg} \mathrm{dia}^{-1}\right)$ & $17,73 \mathrm{a}$ & $16,84 \mathrm{ab}$ & $16,68 \mathrm{ab}$ & $15,99 \mathrm{~b}$ & 16,81 & 5,73 \\
\hline Cms (\%pv) & $3,28 \mathrm{a}$ & $3,11 \mathrm{ab}$ & $3,11 \mathrm{ab}$ & $3,28 \mathrm{~b}$ & 3,13 & 5,77 \\
\hline $\mathrm{Pl}\left(\mathrm{kg} \mathrm{\operatorname {dia } ^ { - 1 } )}\right.$ & $26,62 \mathrm{a}$ & $26,37 \mathrm{a}$ & $24,13 \mathrm{~b}$ & $25,70 \mathrm{ab}$ & 25,70 & 7,10 \\
\hline Plc $\left(\mathrm{kg} \mathrm{dia}^{-1}\right)$ & $24,50 \mathrm{a}$ & $24,41 \mathrm{a}$ & 23,13 a & $23,25 \mathrm{a}$ & 23,82 & 8,00 \\
\hline
\end{tabular}

${ }^{1}=$ Sais de cálcio de ácidos graxos $\left(\right.$ Megalac- $\left.\mathrm{E}^{\circledR}\right)$. Médias seguidas de mesma letra na mesma linha não diferem $(\mathrm{P}>0,05)$ pelo teste de Tukey. 
diferentes fontes de gordura para vacas em lactação e observou que rações contendo sais de cálcio de ácidos graxos apresentaram maior redução no consumo em relação a outras fontes de gordura, como óleos, sementes de oleaginosas e gordura animal, resultado justificado pela menor aceitabilidade dessa fonte de gordura pelos animais. MOALLEM et al. (2007) também observaram menor consumo para vacas suplementadas com sais de cálcio de ácidos graxos em relação a outras fontes de gordura. Segundo o NRC (2001), de uma forma geral, a adição de sais de cálcio de ácidos graxos nas rações de vacas leiteiras resulta em diminuição linear no consumo de matéria seca.

Não houve efeito $(\mathrm{P}>0,05)$ das fontes de gordura nas rações sobre a produção de leite corrigida (Tabela 3). Entretanto, os animais que receberam a ração contendo grão de soja como fonte de gordura apresentaram menor $(\mathrm{P}<0,05)$ produção de leite em comparação com as demais rações utilizadas. Possivelmente esse resultado pode ser atribuído ao menor consumo de energia digestível e menor consumo de energia líquida de lactação para os animais que consumiram essa ração, pois as rações foram formuladas para possuírem a mesma densidade energética e não houve diferença no consumo de matéria de seca entre a ração contendo grão de soja e as demais rações experimentais. Dessa forma, variações no aproveitamento de nutrientes, mais especificamente, o aproveitamento dos ácidos graxos das fontes de gordura pode ter promovido essa redução no desempenho produtivo para o grupo de vacas suplementadas com a ração contendo grão de soja. Alem disso, é preciso enfatizar que o grão de soja utilizado neste estudo apresentou menor concentração de extrato etéreo e maior teor de fibra do que a relatada na literatura (VALADARES FILHO et al., 2006). Muito provavelmente essa composição pode estar relacionada à variedade de soja utilizada, bem como ao período de armazenamento da semente dessa oleaginosa.

As concentrações plasmáticas de glicose e, no soro de triglicerídeos, colesterol-VLDL, proteínas totais, albumina, aspartato aminotransferase (AST), gama glutamil transferase (GGT) e fosfatase alcalina (FA) e albumina não foram influenciadas $(\mathrm{P}>0,05)$ pelas fontes de gordura adicionadas nas rações (Tabela 3 ). Entretanto, as vacas que receberam as rações contendo fontes de gordura apresentaram maiores $(\mathrm{P}<0,05)$ concentrações no soro de colesterol total e colesterolLDL quando comparadas aos animais submetidos à ração controle. A inexistência de variações nas concentrações no soro das enzimas hepáticas AST, GGT e FA indica que neste estudo os animais em lactação suplementados com gordura não sofreram alterações consideráveis no tecido hepático durante o metabolismo de gordura. OLIVEIRA et al. (2005)

Tabela 3 - Médias e coeficientes de variação (cv) das concentrações sanguíneas de glicose (gli), triglicerídeos (tgl), colesterol total (cot), colesterol hdl (c-hdl), colesterol ldl (c-ldl), colesterol vldl (c-vldl), proteínas totais (ptn), albumina (alb), ureia (ure) e nitrogênio ureico no soro (nus), ureia (url) e nitrogênio ureico no leite (nul), gama glutamil transferase (ggt), aspartato aminotransferase (ast) e fosfatase alcalina (fa) em função das rações experimentais.

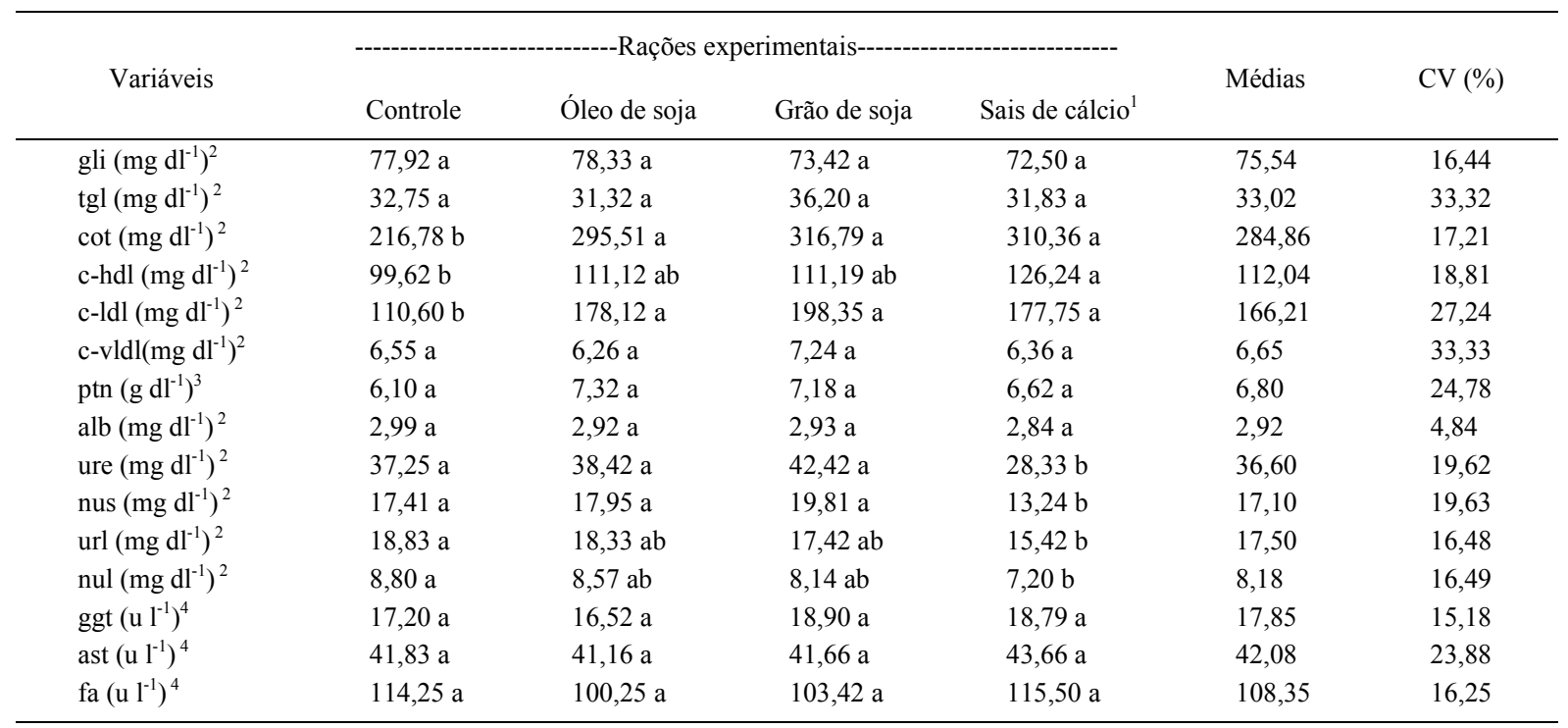

${ }^{1}$ sais de cálcio de ácidos graxos (megalac- $\left.\mathrm{E}^{\circledR}\right)$. médias seguidas de mesma letra na mesma linha não diferem $(\mathrm{P}>0,05)$ pelo teste de tukey. ${ }^{2}$ miligrama por decilitro. ${ }^{3}$ gramas por decilitro. ${ }^{4}$ unidades por litro. 
avaliaram a bioquímica sérica de vacas Holandês no pré e pós-parto e observaram valores normais próximos aos observados neste estudo para as concentrações da enzima GGT, que foi de $13,54 \mathrm{mg} \mathrm{dl}^{-1}( \pm 4,26)$ aos 180 dias de lactação. HOEDEMAKER et al. (2004) avaliaram os parâmetros sanguíneos de 238 vacas e observaram valores da enzima AST de 40,0 $\mathrm{U} \mathrm{L}^{-1}$ aos 77 dias pósparto, valor semelhante ao encontrado neste estudo. De acordo com KANEKO et al. (1997), os valores de FA também estão dentro dos valores encontrados para bovinos, sendo de 0 a $488 \mathrm{U} \mathrm{L}^{-1}$.

Houve aumento da concentração de colesterol-HDL para as vacas alimentadas com as fontes de gordura, especialmente quando comparadas às médias relativas às rações com sais de cálcio de ácidos graxos e controle. Esse aumento da concentração dos componentes do lipidograma colesterol total, colesterolLDL e colesterol-HDL no soro pode ser justificado em razão do maior consumo de ácidos graxos nas rações contendo fontes de gordura, que proporcionou aumento das respectivas frações relativas ao metabolismo de lipídios transportadas no sangue. ELLIOTT et al. (1993), de forma semelhante, observaram aumento da concentração de colesterol total no sangue de vacas com cerca de 64 dias em lactação e suplementadas com diferentes fontes de gordura, com médias de $247 \mathrm{mg} \mathrm{dl}^{-1}$ e $246 \mathrm{mg} \mathrm{dl}^{-1}$, respectivamente, para os níveis de 2,5 e 5,0\% de EE na dieta. De acordo com SCHAUFF et al. (1992) e ELLIOTT et al. (1993), esse aumento da concentração de colesterol total no sangue ocorre em razão da elevação da demanda necessária para digestão, absorção e transporte de ácidos graxos de cadeia longa ingeridos e que estavam presentes nas fontes de gordura. BREMMER et al. (1998) também observaram aumento da concentração de colesterol total em vacas que receberam infusão de misturas de ácidos graxos de cadeia longa no abomaso, de forma semelhante a CHRISTENSEN et al. (1994), que verificaram tendência de aumento da concentração de triglicerídeos em vacas que receberam misturas de ácidos graxos de cadeia longa no abomaso.

A concentração de glicose plasmática não foi influenciada pelas rações experimentais, sendo este resultado semelhante aos estudos de ELLIOTT et al. (1993), BREMMER et al. (1998) e DRACLKEY et al. (1992), que não verificaram variação na concentração de glicose plasmática, em vacas suplementadas com diferentes fontes de gordura. A manutenção da concentração de glicose plasmática se relaciona à relativa estabilidade nas concentrações de glicose em ruminantes, especialmente quando as vacas estão no meio e final de lactação, como as utilizadas no presente estudo.
Houve redução $(\mathrm{P}<0,05)$ da concentração de ureia e nitrogênio uréico no soro para as vacas que receberam sais de cálcio de ácidos graxos como fonte de gordura. Essa redução pode ser atribuída à diminuição no consumo de matéria seca das vacas suplementadas com sais de cálcio quando comparadas com as demais rações experimentais, com exceção da ração contendo grão de soja. De forma semelhante, os animais que receberam as rações contendo sais de cálcio de ácidos graxos apresentaram menor concentração de ureia (URL) e nitrogênio ureico no leite (NUL). Existe alta correlação entre as concentrações de ureia e nitrogênio do soro e do leite. Dessa forma, esse resultado pode ser considerado esperado para as concentrações sanguíneas de URL e NUL. DRACKLEY et al. (1992) e ELLIOTT et al. (1993) não observaram diferença na concentração de nitrogênio ureico no sangue, em vacas recebendo diferentes fontes de gordura nas rações. Segundo esses autores, esse resultado pode ser atribuído à variação do consumo durante o período de fornecimento das rações avaliadas.

Os animais que receberam as rações contendo sais de cálcio de ácidos graxos apresentaram menor $(\mathrm{P}<0.05)$ concentração de uréia no leite (URL) e nitrogênio ureico no leite (NUL). Essa redução pode ser resultado do menor consumo de matéria, o que possivelmente causou maior eficiência de utilização de nitrogênio em nível de rúmen, reduzindo a concentração de nitrogênio no sangue e leite.

\section{CONCLUSÃO}

As concentrações dos parâmetros sanguíneos foram influenciadas pela suplementação de gordura nas rações. As fontes de gordura utilizadas promoveram maior alteração das frações do colesterol, principalmente as lipoproteínas de baixa e alta densidade.

\section{AGRADECIMENTOS}

À Fundação de Amparo à Pesquisa do Estado de São Paulo, pelos recursos concedidos para execução do projeto e ao Conselho Nacional de Desenvolvimento Científico e Tecnológico (CNPq), pela bolsa de mestrado concedida ao primeiro autor.

\section{COMITÊ DE ÉTICA E BIOSSEGURANÇA}

Este estudo foi aprovado pela comissão de Bioética da Faculdade de Medicina Veterinária e Zootecnia da Universidade de São Paulo sob protocolo no 1211/2007 está de acordo com os princípios éticos de experimentação animal. 


\section{REFERÊNCIAS}

ALLEN, M.S. Effects of diet on short-term regulation of feed intake by lactating dairy cattle. Journal of Dairy Science, v.83, n.7, p.1598-1630, 2000. Disponível em: <http:// jds.fass.org/cgi/reprint/83/7/1598. $>$ Acesso em: 15 nov. 2009.

BREMMER, D.R. et al. Effects of chain length and instauration of fatty acid mixtures infused into the abomasums of lactating dairy cows. Journal of Dairy Science, v.81, p.176-188, 1998. Disponível em: <http://jds.fass.org/cgi/reprint/81/1/176>. Acesso em: 15 nov. 2009.

CHRISTENSEN, R.A. et al. Effects of amount of protein and ruminally protected amino acids in the diet of dairy cows fed supplemental fat. Journal of Dairy Science, v.77, p.16181629, 1994. Disponível em: <http://jds.fass.org/cgi/reprint/ 77/6/1618>. Acesso em: 15 nov. 2009.

DIRKSEN, G.; BREITNER, W. New quick-test for semi quantitative determinations of beta-hydroxybutyric acid in bovine milk. Journal Veterinary Medical Animal Physiology Pathology Clinical Medical, v.40, p.779-784, 1993. Disponível em: < http://www.ncbi.nlm.nih.gov/pubmed/ 8135084>. Acesso em: 20 nov. 2009.

DRACKLEY, J.K. et al. Infusion of long-chain fatty acids varying in saturation and chain length into the aboamsum of lactating dairy cows. Journal of Dairy Science, v.75, p.15171526, 1992. Disponível em: <http://jds.fass.org/cgi/reprint/ 75/6/1517>. Acesso em: 20 nov. 2009.

ELLIOTT, J.P. et al. Diets containing high oil corn and tallow for dairy cows during early lactation. Journal of Dairy Science, v.76, p.775-789, 1993. Disponível em: < http:// jds.fass.org/cgi/reprint/76/3/775>. Acesso em: 10 out. 2009.

FRIEDEWALD, W. T. et al. Estimation of the concentration of low-density lipoprotein cholesterol in plasma, without use of the preparative ultracentrifuge, Clinical Chemistry, v.18, p.499-502, 1972. Disponível em: $<$ http://www.clinchem.org/ cgi/reprint/18/6/499. >Acesso em: 10 out. 2009.

GONZÁLEZ, F.H.D. O perfil metabólico no estudo de doenças da produção em vacas leiteiras. Arquivo da Faculdade Veterinária UFRGS, v.25, n.02, p.13-33, 1997. Disponível em: <http:// www6.ufrgs.br/favet/lacvet/restrito/pdf/gonzalez_perfil.pdf $>$. Acesso em: 20 out. 2009.

GUTMANN, I.; BERGMEYER, H.U. Reagents for enzymatic analysis. In: BERGMEYER, H.U.; GAWEHN, K. Methoden der enzymatischen analyse. 3.ed. Weinheim: Verlag Chemie, 1974. V.2, p.1839-1842. Disponível em: <http:/ /www.clinchem.org/cgi/reprint/18/6/499> Acesso em: 20 out. 2009.

HALL, M.B. Making nutritional sense of nonstructural carbohydrate. In: ANNUAL FLORIDA RUMINANT NUTRITION SYMPOSIUM, 9., 1998, Gainsville, Fl. Proceedings... Gainsville: Florida University, 1998. p.108-121.

HOEDEMAKER, M. et al. Peripartal propylene glycol supplementation and metabolism, animal health, fertility, and production in dairy cows. Journal of Dairy Science, v. 87. p.2136-2145, 2004. Disponível em:< http://jds.fass.org/cgi/ reprint/87/7/2136>. Acesso em: 12 set. 2009.
KANEKO. J.J. et al. Clinical biochemistry of domestic animals. 5.ed. San Diego: Academic, 1997. 932p.

MOALLEM, U. et al. Effects of peripartum propylene glycol or fats differing in fatty acid profiles on feed intake, production, and plasma metabolites in dairy cows. Journal of Dairy Science, v.90, n.10, p.3846-3856, 2007. Disponível em: $<$ http:// jds.fass.org/cgi/reprint/90/8/3846>. Acesso em: 20 set. 2009.

NATIONAL RESEARCH COUNCIL - NRC Nutrient requirements of dairy cattle. 7.ed. Washinton, D.C.: National Academic, 2001. 381p.

OLIVEIRA, N.J.F. et al. Hemograma, bioquímica sérica e histologia da biópsia hepática de bovinos após administração de polpa cítrica. Arquivo Brasileiro de Medicina Veterinária e Zootecnia, v.57, n.3, p.418-422, 2005. Disponível em: $<$ http://www.scielo.br/pdf/abmvz/v57n3/25509.pdf>. Acesso em: 20 out. 2009.

ONETTI, S.G.; GRUMMER, R. Response of lactating cows to three supplemental fat sources as affected by forage in the diet and stage of lactation: a meta-analysis of literature. Animal Feed Science and Technology, v.115, p.65-82, 2004. Disponível em: <http://www.sciencedirect.com/science>. Acesso em: 20 out. 2009.

SAS/STAT. User's guide. Release 8.0ed. Cary, 1999. 1500p.

SCHAUFF, D.J. et al. Effects of feeding diets containing calcium salts of long-chain fatty acids to lactating dairy cows. Journal of Dairy Science, v.75, p.2990-3002, 1992. Disponível em: $<$ http://jds.fass.org/cgi/reprint/75/11/3003>. Acesso em: 20 out. 2009.

SILVA, D.J.; QUEIROZ, A.C. Análise de alimentos (métodos químicos e biológicos). Viçosa: UFV, 2002. 235p.

SKLAN, D. et al. Fatty acids, calcium soaps of fatty acids, and cottonseeds fed to high yielding cows. Journal of Dairy Science, v.75, p.2463-2472, 1992. Disponível em: < http:// jds.fass.org/cgi/reprint/75/9/2463>. Acesso em: 20 out. 2009.

SNIFFEN, C.J. et al. A net carbohydrate and protein system for evaluating cattle diets: carbohydrate and protein availability. Journal of Animal Science, v.70, n.12, p.3562-3577, 1992.

STAPLES, C.R. et al. Fat supplementation strategies for lactating dairy cow diets. In: SIMPÓSIO INTERNACIONAL DE BOVINOCULTURA DE LEITE, 2., 2001, Lavras, MG. Anais... Lavras: UFLA, 2001. p.161-178.

VALADARES FILHO, S.C. et al. Tabelas brasileiras de composição de alimentos para bovinos. Viçosa: UFV, 2006. $329 \mathrm{p}$.

VAN SOEST, P.J.; MASON, V.C. The influence of Maillard reaction upon the nutritive value of fibrous feeds. Animal Feed Science and Technology, v.32, n.1, p.4553, 1991. Disponível em: <http://www.sciencedirect.com/ science?_ob=ArticleURL\&>. Acesso em: 20 out. 2009.

WEISS, W.P. et al. A theoretically-based model for predicting total digestible nutrient values of forages and concentrates. Animal Feed Science Technology, v.39, p.95-110, 1992.

WITTWER, F.; CONTRERAS, P.A. Consideraciones sobre el empleo de los perfiles metabólicos en ganado lechero. Archivos de Medicina Veterinaria, v.12, n.1, p.180-188, 1980. 